\title{
Feverfew attenuates carbon tetrachloride-induced testicular damage in rats
}

\author{
Mohammad Mazani $^{1^{\circledR}}$, Shokofeh Banaei ${ }^{2,3}{ }^{\oplus}$, Lotfollah Rezagholizadeh ${ }^{1 *}$ \\ ${ }^{1}$ Department of Biochemistry, School of Medicine, Ardabil University of Medical Sciences, Ardabil, Iran \\ ${ }^{2}$ Department of Physiology, School of Medicine, Ardabil University of Medical Sciences, Ardabil, Iran \\ ${ }^{3}$ Social Determinants of Health (SDH) Research Center, Ardabil University of Medical Sciences, Ardabil, Iran
}

\section{A R T I C L E I N F O}

\section{Article Type:}

Original Article

\section{Article History:}

Received: 9 May 2019

Accepted: 24 August 2019

\section{Keywords:}

Feverfew

Carbon tetrachloride

Testicular damage

Antioxidant

Rat

\begin{abstract}
A B S T R A C T
Introduction: Feverfew is an herbal medicine with a traditional usage of treating several disorders. Some investigations have demonstrated that feverfew is an effective remedy for the prophylactic treatment of inflammatory conditions, migraine and menstrual disorders. Therefore, this study was arranged out to evaluate the protective or curative potentials of feverfew methanolic extract (FME) on carbon tetrachloride $\left(\mathrm{CCl}_{4}\right)$ induced oxidative trauma in testis.

Methods: In this experiment, male Wistar rats were divided into seven groups ( $\mathrm{n}=6)$. Group I as a normal control received $1 \mathrm{~mL} / \mathrm{kg}$ distilled water for 14 days orally and on the 14th day olive oil (1.5 mL/kg, i.p.). Group II received $1 \mathrm{~mL} / \mathrm{kg}$ distilled water orally for 14 consecutive days. Groups III, IV and V animals were pretreatment groups and treated with three different doses of FME (40, 80, and $120 \mathrm{mg} / \mathrm{kg}$, p.o, respectively) for 14 days. All groups except group one, were also intoxicated with $1.5 \mathrm{ml} \mathrm{CCl}_{4}$ (i.p, in a 1:1 dilution with olive oil) on the 14th day. Groups VI and VII were post-treatment groups and received FME (80 and $120 \mathrm{mg} / \mathrm{kg}$, p.o, respectively) at 2, 6, 24 and $48 \mathrm{~h}$ after $\mathrm{CCl} 4$ injection.

Results: Injection of CCl4 significantly $(P<0.001)$ reduced antioxidant enzymes (SOD and $\mathrm{GPx}$ ) and increased malondialdehyde when compared to the control group. Administration of FME significantly $(P<0.05)$ improved these alterations near to control rats.

Conclusion: It is suggested that FME has the ability to protect testis against oxidative damage, possibly through antioxidant effects of its bioactive compounds.
\end{abstract}

Implication for health policy/practice/research/medical education:

Feverfew has potent antioxidant activities such as free radical scavenging potential. Therefore, alcoholic extract of feverfew may be used as a protective agent on testis tissues in carbon tetrachloride induced oxidative stress.

Please cite this paper as: Mazani M, Banaei S, Rezagholizadeh L. Feverfew attenuates carbon tetrachloride-induced testicular damage in rats. J Herbmed Pharmacol. 2020;9(1):42-47. doi: 10.15171/jhp.2020.06.

\section{Introduction}

There are several dysfunctions in male reproductive system such as disorders in shape and motility of sperm and hormonal irregularities like decreasing production of testosterone, which are caused by consumption of alcohol, drug overdose and cigarette abusing (1). Carbon tetrachloride $\left(\mathrm{CCl}_{4}\right)$ is an industrial chemical that causes kidney, lung and testicular damage in experimental animals $(2,3)$. Oxidative trauma is triggered by generated oxygen free radicals from $\mathrm{CCl}_{4}$ decomposition. Free radicals of $\mathrm{CCl}_{4}$ attach to polyunsaturated fatty acid (PUFA) of sperm membrane to generate alkoxy and peroxy radicals that, in turn, induce lipid peroxides, that are highly reactive, modify sperm concentration, decrease antioxidant enzyme activities and lead to damage or necrosis (1). Free radicals induce apoptosis and necrosis of spermatocytes/spermatids and collapse in seminiferous tubules $(4,5)$.

Medicinal plants are also popular to utilize due to functional food or biopharmaceuticals properties. Currently, different medicinal plants have been investigated based on the complementary method on drug development from Ayurveda (6-8). Several medicinal plants like Matricaria chamomilla L. are used as potent antioxidants against chemical induced oxidative stress (9). Feverfew (Tanacetum parthenium) is a medicinal herb with a traditional usage of curing a kind of disease. Recent studies have revealed feverfew to be a beneficial medicinal 
plant for the prophylactic treatment of migraine, women's ailments, inflammatory conditions, menstrual disorders and the production of prostaglandins, thromboxanes and leukotrienes (10). Many researchers have reported that the bioactive component responsible for the pharmacological impacts is parthenolide, a sesquiterpene lactone found in feverfew $(11,12)$. In addition to parthenolide, feverfew contains other significant constituents such as aromatic compounds and flavonoids. Furthermore, leaves and flowers of feverfew are composed of lipophilic flavonoids, such as quercetagetin 3,6-dimethyl ether, 6-hydroxykaempferol 3,6-dimethyl ether, and 6-hydroxykaempferol 3,6,40-trimethyl ether (santin) (13).

It is obvious that, several polyphenolic and flavonoid compounds have antioxidant activities such as free radical scavenging capacities via minimizing the reactive oxygen species and other free radicals generated by aerobic metabolism (14). However, to our knowledge, there is no information available for the testo-protective and testo-curative activities of feverfew extract and its major bioactive constituents on oxidative stress. Here, testis toxicity was induced by administration a single dose of $\mathrm{CCl}_{4}$ into experimental adult male Wistar rats and radical scavenging activity of the extract was evaluated by measuring the levels of antioxidant and extent of lipid peroxidation in testis tissue homogenates and activity of antioxidant enzymes via superoxide dismutase (SOD) and glutathione peroxidase (GPX).

Therefore major aim of the present study was to investigate the protective mechanisms of alcoholic extract of feverfew on testis tissues in carbon tetrachloride intoxicated rats.

\section{Materials and Methods}

Chemicals

A commercial SOD and GPX kit was purchased from Randox Laboratories Ltd (Crumlin, UK). Thiobarbituric acid, trichloroacetic acid and bovine serum albumin were purchased from Merck (Germany). All other chemicals and reagents used in this study were of analytical grade.

\section{Plant collection and extraction}

Feverfew was collected from the Vigan village, Arasbaran region, Iran, $2100 \mathrm{~m}$ above sea level, during its flowering season on 5 May 2015. Plants were identified and a specimen was submitted to herbarium of eastern Azerbayjan natural resource and agriculture research center with herbarium code 2411, then it was prepared for extraction. Whole plants (leaves, stem and flowers) were shade dried at room temperature for two weeks, chopped, ground mechanically of mesh size $1 \mathrm{~mm} .1 \mathrm{~kg}$ powder of feverfew was extracted in 5 liter of aqueous methanol (30:70) with random shaking, after a week the extract was filtered through Whatman filter paper No. 45, filtrate was mixed and evaporated through rotary vacuum evaporator at $45^{\circ} \mathrm{C}$ to get concentrated extraction. Then, it was converted to dry powder using freeze dryer for 2 weeks under main drying and final drying. The crude extract was stored in air tight container. The aqueous extract of feverfew was prepared fresh each time after triturating with distilled water immediately before the administration.

\section{Experimental animals}

Forty-two male Wistar rats, weighing between $180 \pm 20 \mathrm{~g}$, were used for the study. The animals were procured from the animal house of Tehran veterinary medicine school and were kept at the animal house in Ardabil University of medical science, Ardebil, Iran. After randomization into various groups, the rats were acclimatized for a period of 7 days under standard husbandry conditions at room temperature $\left(25 \pm 3{ }^{\circ} \mathrm{C}\right)$ and 12 hours light/dark cycle. All the animals were fed under strict hygienic conditions with rodent pellet diet and water ad libitum.

\section{Experimental design}

A total of 42 rats were divided into 7 groups of 6 rats each. Group I served as a normal control for both prophylactic and curative studies and received distilled water for 14 days orally and on the $14^{\text {th }}$ day olive oil ( $1.5 \mathrm{~mL} / \mathrm{kg}$, i.p.). Group II served as a toxic control for both prophylactic and curative studies and received distilled water for 14 days orally and on the $14^{\text {th }}$ day $\mathrm{CCl}_{4}(1.5 \mathrm{~mL} / \mathrm{kg}$ i.p.) in 1:1 dilution with olive oil. Groups III, IV and V served as pre-treatment groups (prophylactic). They received methanolic extract of feverfew at doses of 40,80 and $120 \mathrm{mg} / \mathrm{kg}$, orally for 14 days, respectively, and on the $14^{\text {th }}$ day received $\mathrm{CCl}_{4}(1.5 \mathrm{~mL} / \mathrm{kg}$ i.p. $)$ in $1: 1$ dilution with olive oil, 2 hours after administration of the last dose of extract. Groups VI and VII served as post-treatment groups (curative). They received distilled water orally for 14 days and on the $14^{\text {th }}$ day received $\mathrm{CCl}_{4}(1.5 \mathrm{~mL} / \mathrm{kg}$ i.p.) in a 1:1 dilution with olive oil, followed by a methanolic extract of feverfew at a dose of $80 \mathrm{mg} / \mathrm{kg}$ (Group VI) or $120 \mathrm{mg} / \mathrm{kg}$ (Group VII) orally at 2, 6, 24, and 48 hours after $\mathrm{CCl}_{4}$ intoxication. All rats were sacrificed 50 hours after $\mathrm{CCl}_{4}$ administration. Just before sacrifice, blood was collected from the heart under mild ketamine anesthesia.

\section{Testis homogenates}

Fifty hours after the $\mathrm{CCl}_{4}$ injection, all the animals were anesthetized with ketamin $10 \%$ and sacrificed. After the rats were killed, their testis tissues were dissected out and washed with ice-cold normal saline to completely remove all the blood cells. Then, they were cut into small pieces, one piece placed in $50 \mathrm{mM}$ Tries buffer ( $\mathrm{pH}$ 7.4) and homogenized using Heidolph (Silent Crusher) homogenizer to obtain $10 \%$ homogenate. The homogenate was centrifuged at $3000 \mathrm{rpm}$ for 1 minute. The supernatant was collected and transferred to an 
Eppendorf tube and was centrifuged at $12000 \mathrm{rpm}$ for 20 minutes (Eppendorf, $5810 \mathrm{R}$ ). The supernatant was used for the determination of malondialdehyde (MDA) as a lipid peroxidation marker, SOD and GPX.

Determination of lipid peroxide level

Lipid peroxidation level in the testis homogenate was determined as thiobarbituric acid reactive substances (TBARS) by measuring MDA level spectrophotometrically (Ependorf, Ecom-E6125) according to Mihara \& Uchiyama method (15). Briefly, $0.5 \mathrm{~mL}$ supernatant of testis homogenate was mixed with $2400 \mathrm{~mL}$ of $1 \%$ aqueous orthophosphoric acid solution and $1 \mathrm{~mL}$ of $0.67 \%$ thiobarbituric acid (TBA) solution in water, and heated in a boiling water bath for 45 minutes. The pink-colored chromogen formed by the reaction of TBA with MDA was extracted by n-butanol and measured at $532 \mathrm{~nm}$. The results were expressed as MDA (nmol/mg prot) (15).

\section{SOD and GPX measurement}

Commercial kits were used to determine SOD and GPx activities (Randox Laboratories, UK). In the SOD method, uric acid and superoxide radical were produced from xanthine with the reaction catalyzed by xanthine oxidase at $505 \mathrm{~nm}$. The superoxide radicals were produced in this reaction with 2-(4-iodophenyl)-3-(4-nitrophenyl) -5- phenyl tetrazolium chloride (INT) to produce a red formazan compound. Tissue SOD enzyme activity correlates with the degree of inhibition of this reaction. In the GPx method, oxidized glutathione is reduced by glutathione reductase in the presence of NADPH. At the same time, NAPDH is oxidized to NADP. The change in absorbance at $340 \mathrm{~nm}$ is dependent on the decrease in reduced NADPH that is measured spectrophotometrically (T80+UV/Vis spectrometer PG Instrument) (9).

Total protein measurement

Protein concentrations in the samples were measured by the Bradford method using concentrated Coomassie blue reagent. Bovine serum albumin was used as the standard (16).

\section{Histopathological evaluation}

The testis tissue was collected and fixed in 10\% formalin, dehydrated in graduated ethanol (50-100\%), cleared in xylene, and embedded in paraffin. Sections of 4-5 $\mu \mathrm{m}$ thick were prepared and then stained with hematoxylin and eosin (H\&E) color and examined for histopathological changes under the microscope (Olympus IX71).

\section{Statistical analysis}

Statistical analysis was performed using one-way analysis of variance (ANOVA) followed by post hoc LSD complementary test to correct for multiple comparison treatments, using the SPSS for Windows statistical package, version 16.0 (SPSS Inc. Chicago, IL, USA). The value of significant difference was considered at $P<0.05$. Appropriate graphs were plotted using Microsoft Excel 2013.

\section{Results}

The effect of FME on testis antioxidant profile

Antioxidant profile plays an important role in infertility. The effects of feverfew methanolic extract (FME) against $\mathrm{CCl}_{4}$ induced antioxidant status alteration are shown in Figure 1. Activities of antioxidant enzymes such as GPX and SOD were significantly $(P<0.01)$ reduced by treatment of $\mathrm{CCl}_{4}$ as compared to control group. This reduction was improved significantly $(P<0.01)$ by preand post-administration of FME near to control group.

The effect of FME on testis MDA

The effects of $\mathrm{CCl}_{4}$ and the protective and curative effects of FME on tissue MDA are shown in Figure 2. $\mathrm{CCl}_{4}$ treatment to rats significantly $(P<0.01)$ increased the contents of MDA in tissue homogenate as compared to control group. $80 \mathrm{mg} / \mathrm{kg}$ and $120 \mathrm{mg} / \mathrm{kg}$ FME showed significant protection and decreased the contents of MDA in a dose dependent manner.

The effect of FME and $\mathrm{CCl}_{4}$ on the histology of testis Histological appearance plays an important role in the study of the protective role of FME in rats. Administration of $\mathrm{CCl}_{4}$ caused sloughing of cells as well as atrophy of seminiferous tubules. Oral treatment with FME revealed a marked repairing of testicular abnormalities induced by $\mathrm{CCl}_{4}$ in dose dependent way near to control group (Figure 3).

\section{Discussion}

$\mathrm{CCl}_{4}$ is metabolized by phase I cytochrome P450 system

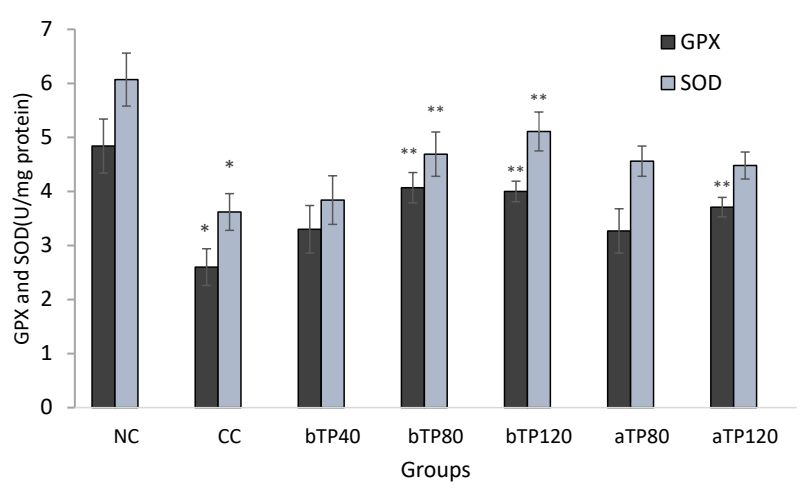

Figure 1. Effect of feverfew methanolic extract (FME) on testis antioxidant enzymes in $\mathrm{CCl}_{4}$ intoxicated rats. NC: Normal control; $\mathrm{CC}$ : $\mathrm{CCl}_{4}$ treated group; bTP40, bTP80 and bTP120: $\mathrm{CCl}_{4}$-treated rat predosed by FME at $40 \mathrm{mg} / \mathrm{kg}, 80 \mathrm{mg} / \mathrm{kg}$ and $120 \mathrm{mg} / \mathrm{kg}$, respectively; aTP80 and aTP120: $\mathrm{CCl}_{4}$-treated rat post-dosed by FME at $80 \mathrm{mg} / \mathrm{kg}$ and 120 $\mathrm{mg} / \mathrm{kg}$, respectively.

${ }^{*} P<0.001$ compared to the normal control group (NC).

${ }^{* *} P<0.05$ compared to the toxin control group (CC). 


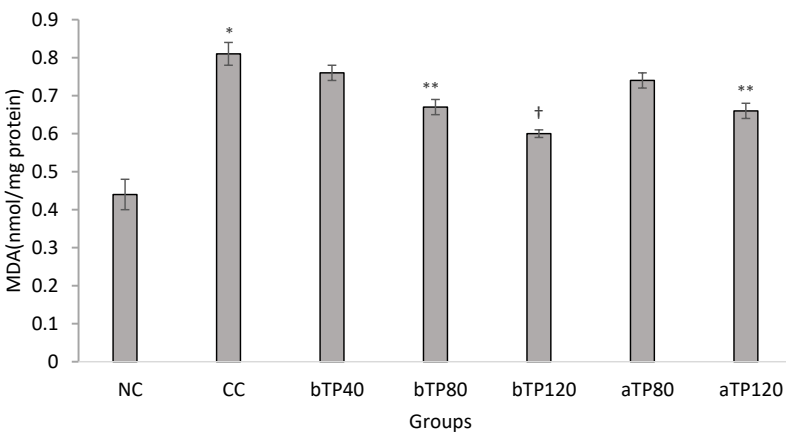

Figure 2. Effect of feverfew methanolic extract (FME) on testis MDA in $\mathrm{CCl}_{4}$ intoxicated rats. NC: Normal control; $\mathrm{CC}$ : $\mathrm{CCl}_{4}$ treated group; bTP40, bTP80 and bTP120: $\mathrm{CCl}_{4}$-treated rats pre-dosed by FME at 40 $\mathrm{mg} / \mathrm{kg}, 80 \mathrm{mg} / \mathrm{kg}$ and $120 \mathrm{mg} / \mathrm{kg}$, respectively; aTP80 and aTP120: $\mathrm{CCl}_{4}-$ treated rats post-dosed by FME at $80 \mathrm{mg} / \mathrm{kg}$ and $120 \mathrm{mg} / \mathrm{kg}$ respectively.

${ }^{*} P<0.001$ compared to the normal control group (NC).

** $P<0.05$ compared to the toxin control group (CC).

${ }^{\dagger} P<0.001$ compared to the toxin control group (CC).

to generate reactive metabolic trichloromethyl radical $(\mathrm{CCl} 3 *)$ and peroxy trichloromethyl radical $\left({ }^{*} \mathrm{OOCCl} 3\right)$. These free radicals can attach to PUFA to form alkoxy $\left(\mathrm{R}^{*}\right)$ and peroxy radicals (ROO*), that are highly reactive and, in turn, create lipid peroxides, alter enzyme activity and finally cause different injury or necrosis $(17,18)$. Carbon tetrachloride-induced injury is created from free radicals through lipid peroxidation of cell membranes, decreases antioxidant enzymes and antioxidant substrates to induce oxidative stress. That is a significant factor in acute and chronic injury in numerous organs.

Feverfew possesses bioactive compounds which play a major role in minimizing the oxidative stress in male wistar rats. Testicular oxidative stress is a typical factor in infertility. It is suggested that feverfew may be effective for developing better antioxidant therapies for several reproductive diseases such as hypo-spermatogenesis $(19,20)$. The results of the present study discovered that FME had significant impact on antioxidant enzymes and histopathology of testis. The ameliorative effect of FME may be due to flavonoids and polyphenolic compounds. Antioxidant enzymes play a major role in oxidative infertility. Oxidative stress causes overproduction of oxygen free radicals and disturbance in better function of the antioxidant system (21). $\mathrm{CCl}_{4}$ and oxygen free-radical production is associated with inadequate enzymatic and non-enzymatic antioxidant status $(22,23)$.

The results of our present investigation showed that $1.5 \mathrm{~mL} / \mathrm{kg} \mathrm{CCl}$ administration in rats caused significant reduction in the activity of antioxidant enzymes (SOD and GPX) and increased MDA. The decrease of antioxidant enzymes activities in testicular tissue might be due to the accumulation of free radicals that cause enhanced lipid peroxidation or inactivation of the antioxidative enzymes. Administration of FME also enhanced the levels of antioxidant enzymes in $\mathrm{CCl}_{4}$ treated rats. It seems

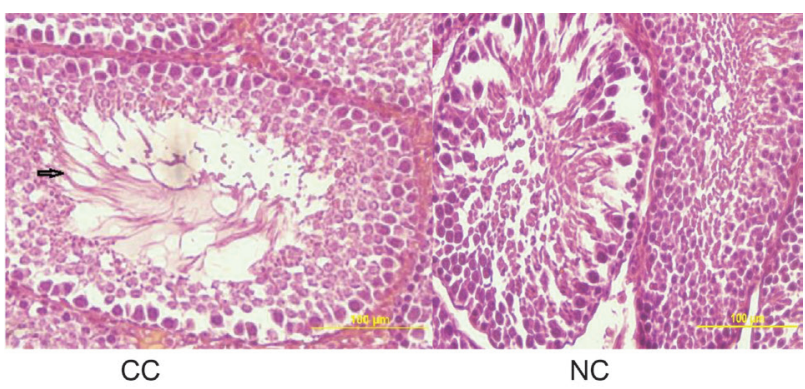

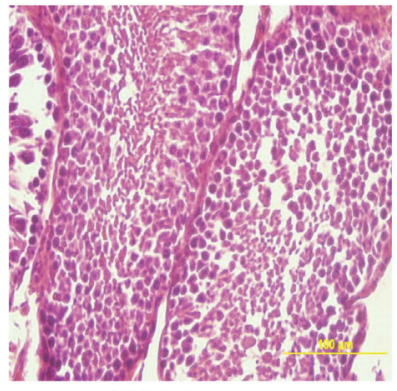

bTP80

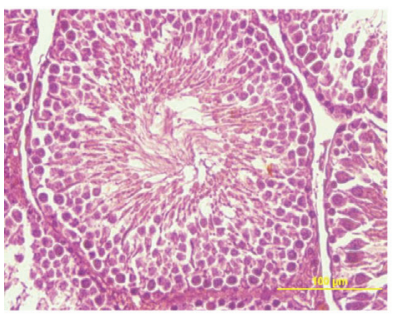

bTP120

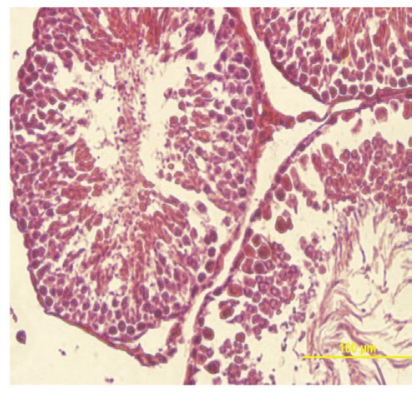

bTP40

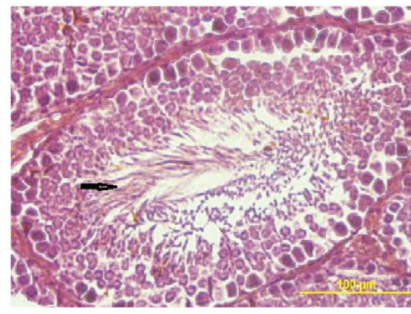

aTP80

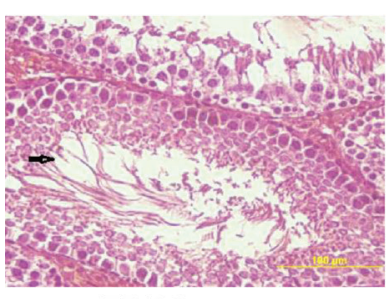

aTP120

Figure 3. Effects of everfew methanolic extract (FME) on carbon tetrachloride $\left(\mathrm{CCl}_{4}\right)$ induced oxidative trauma in testis. Testis tissues were stained with H\&E. NC: Normal control; CC: CCl4 treated group; bTP40, bTP80 and bTP120: CCl4-treated rats pre-dosed by FME at $40 \mathrm{mg} / \mathrm{kg}, 80$ $\mathrm{mg} / \mathrm{kg}$ and $120 \mathrm{mg} / \mathrm{kg}$ respectively; aTP80 and aTP120: $\mathrm{CCl}_{4}$-treated rats post-dosed by FME at $80 \mathrm{mg} / \mathrm{kg}$ and $120 \mathrm{mg} / \mathrm{kg}$, respectively. The arrows show degeneration on the photomicrographs.

to be due to the presence of phenolic and polyphenolic constituents which may have several active properties such as scavenging of active oxygen species, prevention of the production of free radicals and chain neutralizing activity. Similar results were also reported with Launaea procumbens extract on the level of MDA in rats after $\mathrm{CCl}_{4}$ exposure (1). The protective impact may be related to antioxidant, gene expression and beneficial effect in metabolic pathways.

Histopathological evaluation revealed marked 
degeneration and sloughing of germ cells in $\mathrm{CCl}_{4}$ treated group; however, administration of feverfew extract showed significant improvement in histopathological modifications created by $\mathrm{CCl}_{4}$ in testis sections. The histological modifications in samples of rats receiving $\mathrm{CCl}_{4}$ are comparable with Khan results (1) who studied the effect of Launaea procumbens extract against $\mathrm{CCl}_{4}$ induced toxicity on the rat's testes. Additionally, Yousef and Salama (20) revealed that oxidative stress resulting from the overproduction of oxygen radicals leads to testis damage. Different conditions related to male infertility are stimulants of oxidative stress, which leads to an increase in germ cell apoptosis, necrosis and hypo-spermatogenesis. Reducing the harmful impact of $\mathrm{CCl}_{4}$ by FME treatment may be due to the flavonoids in FME, which display many health-promoting effects, including the ability to increase intercellular antioxidant levels, decrease capillary permeability and scavenge oxidants and free radicals.

\section{Conclusion}

$\mathrm{CCl}_{4}$-induced injury is created from free radicals through lipid peroxidation of cell membranes, decreased antioxidant enzymes and antioxidant substrates to induce oxidative stress. That is a significant factor in acute and chronic injury in numerous organs. Feverfew possesses bioactive compounds which play a major role in minimizing the oxidative stress. Therefore, it is suggested that feverfew has the ability to protect testis against oxidative damage, possibly through antioxidant effects of its bioactive compounds.

\section{Authors' contributions}

MM: study design; SB: histological evaluation and manuscript writing; LR: biochemical and statistical analysis. All authors read and approved the final manuscript.

\section{Conflict of interests}

The authors declare no conflict of interest.

\section{Ethical considerations}

The animal experiments ethics committee approved the study (Approval number IR.ARUMS.REC.1394.67). The study was conducted in accordance with the Guide for the Care and Use of Laboratory Animals published by the US National Institutes of Health.

\section{Funding/Support}

This study was financially supported by Ardabil University of Medical Sciences.

\section{References}

1. Khan RA. Protective effects of Launaea procumbens on rat testis damage by CCl4. Lipids Health Dis. 2012;11(1):1-8. doi: 10.1186/1476-511X-11-103.

2. Sönmez M, Türk G, Çeribaşı S, Çiftçi M, Yüce A, Güvenç
$\mathrm{M}$, et al. Quercetin attenuates carbon tetrachloride-induced testicular damage in rats. Andrologia. 2014;46(8):848-58. doi: 10.1111/and.12159.

3. Jiang L, Huang J, Wang Y, Tang H. Metabonomic analysis reveals the CCl4-induced systems alterations for multiple rat organs. J Proteome Res. 2012;11(7):3848-59. doi: 10.1021/pr3003529.

4. Horn MM, Ramos AR, Winkelmann L, Matte US, Goldani HA, Silveira TR. Seminiferous epithelium of rats with food restriction and carbon tetrachloride-induced cirrhosis. International Braz J Urol. 2006;32(1):94-9. doi: 10.1590/ s1677-55382006000100016.

5. Qureshi R, Bhatti GR. Ethnobotany of plants used by the Thari people of Nara Desert, Pakistan. Fitoterapia. 2008;79(6):468-73. doi: 10.1016/j.fitote.2008.03.010.

6. Calixto J. Efficacy, safety, quality control, marketing and regulatoryguidelinesforherbalmedicines (phytotherapeutic agents). Braz J Med Biol Res. 2000;33(2):179-89.

7. Mallhi TH, Abbas K, Ali M, Qadir MI, Saleem M, Khan YH. Hepatoprotective activity of methanolic extract of Malva parviflora against paracetamol-induced hepatotoxicity in mice. Bangladesh J Pharmacol. 2014;9(3):342-6. doi: 10.3329/bjp.v9i3.19105.

8. Jadeja RN, Chanu TM, Jadav SV, Patel MD, Patel DK, Salunke SP, et al. Toxicological evaluation and hepatoprotective potential of Clerodendron glandulosum. Coleb leaf extract. Hum Exp Toxicol. 2011;30(1):63-70. doi: 10.1177/0960327110368420.

9. Aksoy L, Sözbilir NB. Effects of Matricaria chamomilla L. on lipid peroxidation, antioxidant enzyme systems, and key liver enzymes in CCl4-treated rats. Toxicol Environ Chem. 2012;94(9):1780-8. doi: 10.1080/02772248.2012.729837.

10. Sharopov FS, Setzer WN, Isupov SJ, Wink M. Composition and bioactivity of the essential oil of Tanacetum parthenium from a wild population growing in Tajikistan. Am J Essent Oils Nat Prod. 2015; 2(4): 32-34.

11. Williams CA, Harborne JB, Geiger H, Hoult JRS. The flavonoids of Tanacetum parthenium and T. vulgare and their anti-inflammatory properties. Phytochemistry. 1999;51(3):417-23.

12. Wu C, Chen F, Wang X, Kim H-J, He G-q, Haley-Zitlin $\mathrm{V}$, et al. Antioxidant constituents in feverfew (Tanacetum parthenium) extract and their chromatographic quantification. Food Chem. 2006;96(2):220-7.

13. Pareek A, Suthar M, Rathore GS, Bansal V. Feverfew (Tanacetum parthenium L.): A systematic review. Pharmacogn Rev. 2011;5(9):103. doi: 10.4103/09737847.79105 .

14. Jain NK, Kulkarni SK. Antinociceptive and antiinflammatory effects of Tanacetum parthenium L. extract in mice and rats. J Ethnopharmacol. 1999;68(1):251-9.

15. Uchiyama M, Mihara M. Determination of malonaldehyde precursor in tissues by thiobarbituric acid test. Anal Biochem. 1978;86(1):271-8. doi: 10.1016/00032697(78)90342-1.

16. Bradford MM. A rapid and sensitive method for the quantitation of microgram quantities of protein utilizing the principle of protein-dye binding. Anal Biochem. 1976;72(1-2):248-54. doi: 10.1006/abio.1976.9999.

17. Sahreen S, Khan MR, Khan RA. Hepatoprotective effects 
of methanol extract of Carissa opaca leaves on $\mathrm{CCl}$ 4-induced damage in rat. BMC Complement Altern Med. 2011;11(48):1-9. doi: 10.1186/1472-6882-11-48.

18. Vuda M, D’Souza R, Upadhya S, Kumar V, Rao N, Kumar V, et al. Hepatoprotective and antioxidant activity of aqueous extract of Hybanthus enneaspermus against CCl4-induced liver injury in rats. Exp Toxicol Pathol. 2012;64(7):855-9. doi: 10.1016/j.etp.2011.03.006.

19. Turner TT, Lysiak JJ. Oxidative stress: a common factor in testicular dysfunction. J Androl. 2008;29(5):488-98. doi: 10.2164/jandrol.108.005132.

20. Yousef MI, Salama AF. Propolis protection from reproductive toxicity caused by aluminium chloride in male rats. Food Chem Toxicol. 2009;47(6):1168-75. doi: 10.1016/j.fct.2009.02.006.

21. Eshaghi M, Zare S, Banihabib N, Nejati V, Farokhi F, Mikaili P. Cardioprotective effect of Cornus mas fruit extract against carbon tetrachloride induced-cardiotoxicity in albino rats. J Basic Appl Sci Res. 2012;2(11):11106-14.

22. Sahreen S, Khan MR, Khan RA, Alkreathy HM. Cardioprotective role of leaves extracts of Carissa opaca against $\mathrm{CCl} 4$ induced toxicity in rats. BMC Res Notes. 2014;7:224. doi: 10.1186/1756-0500-7-224.

23. Matin S, Nemati A, Ghobadi H, Alipanah-Moghadam R, Rezagholizadeh L. The effect of conjugated linoleic acid on oxidative stress and matrix metalloproteinases 2 and 9 in patients with COPD. Int J Chron Obstruct Pulmon Dis. 2018;13:1449-54. doi: 10.2147/COPD.S155985. 